\title{
From Paradigm-Based Explanation to Pragmatic Genealogy
}

\author{
MATTHIEU QUELOZ
}

Why would philosophers interested in the points or functions of our conceptual practices bother with genealogical explanations if they can focus directly on paradigmatic examples of the practices we now have? To answer this question, I compare the method of pragmatic genealogy advocated by Edward Craig, Bernard Williams, and Miranda Fricker-a method whose singular combination of fictionalising and historicising has met with suspicion-with the simpler method of paradigm-based explanation. Fricker herself has recently moved towards paradigm-based explanation, arguing that it is a more perspicuous way of reaping the same explanatory pay-off as pragmatic genealogy while dispensing with its fictionalising and historicising. My aim is to determine when and why the reverse movement from paradigm-based explanation to pragmatic genealogy remains warranted. I argue that the fictionalising and historicising of pragmatic genealogy is well-motivated, and I outline three ways in which the method earns its keep: by successfully handling historically inflected practices which paradigm-based explanation cannot handle; by revealing and arguing for connections to generic needs we might otherwise miss; and by providing comprehensive views of practices that place and relate the respects in which they serve both generic and local needs.

$\mathrm{P}$ HILOSOPHERS seeking to understand the points or functions of our practices of living by certain concepts, values, and virtues-our conceptual practices-face a choice: should they turn directly to the history-laden tangle of our actual practices and try to discern the point of individual elements? Or should they approach our practices indirectly, via the prior or prototypical forms out of which they have developed? It is the latter form of point-based explanation that was advocated by Edward Craig (1990,1993), Bernard Williams (2002), and Miranda Fricker (2007). They sought to identify, respectively, the point of the concept of knowledge, the point of valuing the truth, and the point of the virtue of testimonial justice by offering what I shall call pragmatic 
genealogies: fictionalising and historicising narratives that first reveal the point, for creatures like us, of a simple prototype of a conceptual practice in a fictional 'state of nature' before explaining -in a way that may, as in Williams's case, increasingly involve actual history-how this prototype might have developed into the practice we actually have. ${ }^{1}$

But even philosophers sympathetic to genealogical explanations have tended either to endorse the historicising while failing to see the point of the fictionalising (Dutilh Novaes 2015; Hacking 2005, p. 168; Koopman 2009; 2013, p. 71), or to endorse the fictionalising while seeing no real need for the historicising (Blackburn 2013b; Craig 2007; Price 2011; M. Williams 2013). ${ }^{2}$ This is why, more recently, Miranda Fricker has moved away from pragmatic genealogy towards a nongenealogical sibling of the method which directly moves in on our actual conceptual practices and thereby dispenses with the singular mixture of historicising and fictionalising that philosophers have been reluctant to adopt. This pared-down, non-genealogical method is what Fricker calls paradigm-based explanation: focusing on a real and paradigmatic instance of a current practice, we hypothesise its point and use it to explain further forms of the practice as derivatives of the paradigm case that serve the same overarching point in different ways. Paradigm-based explanation is explicitly offered 'as a more straightforward and transparent way of achieving the very same explanatory pay-off' (Fricker Forthcoming, p. 4) that pragmatic genealogies achieve with their fictionalising and historicising. But if the same pay-off can be reaped with a simpler

1 In Queloz (2018b), I offer a reconstruction of Williams's genealogy explaining how it can coherently involve itself in history while remaining a pragmatic genealogy starting out from a fictional state of nature. For a reconstruction of Craig's genealogy as a pragmatic genealogy, see Queloz (2019). For a disambiguation of the notion of the point of conceptual practices, see Queloz (Forthcoming).

2 Some, like Elizabeth Fricker, take issue with genealogising of any kind in a pointbased explanation (Fricker 2015), while others see no point in pursuing point-based explanations (Kornblith 2011). 
approach, why should someone interested in identifying the points of conceptual practices bother with genealogy? Why should we go in for the fictionalising and historicising if they are just unnecessary complications?

My aim in this paper is to offer an account of pragmatic genealogy which defends the method's place in our repertoire alongside its nongenealogical sibling and which vindicates its fictionalising as well as its historicising. ${ }^{3}$ I aim to show when and why someone interested in the point of our conceptual practices has reason to move from paradigmbased explanation to pragmatic genealogy. To this end, I argue that the fictionalising and historicising of pragmatic genealogy proves its worth by allowing us to deal with historically inflected conceptual practices which lack a paradigm case or an obvious connection to generic human needs.

I proceed as follows: in $\S 1$, I develop a taxonomy of four increasingly complex forms of point-based explanation which allows us to make sense of genealogical fictionalising and historicising as well-motivated elaborations of paradigm-based explanation. In §2, I contrast Fricker's interpretation of pragmatic genealogies as elaborate ways of achieving the same explanatory pay-off as paradigm-based explanations with a different interpretation of pragmatic genealogies on which their explanatory reach goes beyond that of paradigm-based explanations.

3 I thereby defend pragmatic genealogy against a wider set of approaches, because Fricker's paradigm-based explanation is emblematic of a range of methods that similarly try to get at the point of a conceptual practice synchronically rather than genealogically: practical explication as characterised by Kappel (2010) and Gardiner (2015), for example, or Elizabeth Fricker's current-role account of concepts (2015), or the neo-pragmatist explanations of various types of discourse in terms of their functions advocated by Blackburn (2013a, 2013b), Price (2011; 2013), M. Williams (2013) and Misak (2015) among others. What makes Miranda Fricker's version particularly apt for my purposes is that she comes to paradigm-based explanation from pragmatic genealogy. 
I argue for three claims: (i) pragmatic genealogies get a grip even where a paradigm case is lacking by constructing a prototype; (ii) pragmatic genealogies need not assume that generic human needs are still informative, but can offer an argument for this; (iii) insofar as elucidations of our current ways of going on in light of generic human needs come up short due to historical change, pragmatic genealogies can remedy this by augmenting the explanations with local needs.

\section{Four Types of Point-Based Explanation}

Miranda Fricker (2016, Forthcoming) argues that when dealing with conceptual practices that are internally diverse, held together by crisscrossing relations of family-resemblance rather than a common core, the standard approach of conceptual analysis is the wrong approach to take. Conceptual analysis aims to spell out definitions in terms of necessary and sufficient conditions, to be measured against our current intuitions about what falls under a given concept. Any feature that is not strictly a necessary condition will eventually fall prey to counterexamples and drop out of the final analysis. But why should we assume that all and only instances of a concept share a set of features explaining why they are subsumable under that concept? Boiling them down to their highest common factor is likely to leave us either with a definition that is too thin to be informative, or with no definition at all. This worry is familiar enough, but Fricker then makes a further point: even where definitions in terms of necessary and sufficient conditions are available, the features that are illuminating for the purposes of philosophy may not all be among the necessary conditions (2016, p. 166). Why something exists, how it functions, and what its value is, may well be best explained by features which, though characteristic, distinctive, or typical, are not 
invariably present. Even when conceptual analysis is possible, therefore, it may not be our best option.

This is why Fricker adapts from Craig (1990) and Williams (2002) the idea that when dealing with a phenomenon that is internally diverse, such as the practice of blame, we should seek to make sense of it in terms of the point it serves in paradigm cases rather than to try and define it in terms of necessary and sufficient conditions. To grasp the point of a practice, on this view, is to understand the most salient useful difference it makes to the lives of the creatures engaging in that practice, where usefulness is cashed out in terms of the practice's tendency to help satisfy the needs of these creatures. It is to grasp what the practice adds, and consequently also what would be lost if it were abandoned. Viewing our practices of living by certain concepts, values, or virtues as akin to tools or techniques, we can ask what they do for us. The diversity that stood in the way of conceptual analysis then becomes intelligible as reflecting the diversity of conditions under which these techniques typically serve a function, conditions which need be neither necessary nor sufficient. This approach imposes order on the practice while accounting for its internal diversity by exhibiting its various features as more or less directly subservient to an overarching point.

In Fricker's paradigm-based explanation of blame, the paradigm case is Communicative Blame: $A$ wrongs $B$ and $B$ tells $A$ with feeling that $A$ is at fault. The point of this, according to Fricker, is to align $A$ 's and $B$ 's moral sensibilities (2016, p. 167). She seeks to derive an understanding of other types of blame, such as self-blame or blame of absent third parties, from our understanding of Communicative Blame, giving us an explanatory grip on the practice by organising it around the paradigm case. But besides being explanatorily basic, the paradigm case is also presented as forming a direct response to a practical need for moral alignment: given that need, Communicative Blame is shown 
to be near-indispensable or necessary. This allows us to rationalise the practice by revealing why we go in for it; and it allows us to differentiate between its more basic and indispensable manifestations and its more derivative and contingent manifestations. To realise whether and how a practice responds to certain needs is also to realise that, insofar as these are needs we are identified with, they provide reasons to engage in the practice. As a result, we acquire a critical grip on the practice: we come to see which forms of the practice we have strong reasons to engage in because they answer to practical exigencies, and which might sensibly be put into question or even taxed as dysfunctional. ${ }^{4}$

On the interpretation of pragmatic genealogy I wish to defend, it is best understood as an elaboration of paradigm-based explanation. It goes beyond the ground it shares with paradigm-based explanation in two respects: (a) it constructs models, in particular hypothetical prototypes of our conceptual practices; and (b) it introduces a dynamic dimension to help us understand how we might have got from these prototypes to the practices we actually have. ${ }^{5}$ These are the two senses in which pragmatic genealogy can rightly be said to fictionalise and to historicise.

How pragmatic genealogy forms an elaboration of paradigm-based explanation becomes evident if we juxtapose them along with their intermediaries: ${ }^{6}$

4 I say more about the sense in which needs provide reasons to engage in a practice or particular forms of a practice in Queloz (2018a). For a nuanced discussion of how genealogies can provide reasons for or against beliefs, see Srinivasan (2015).

5 Recent examples of pragmatic genealogies include Kusch and McKenna (2018b); Pettit (2018).

6 For a related taxonomy of what I call point-based explanations, see Gardiner (2015). Her 'practical explication' corresponds to my (1), while her 'hypothetical genealogical teleology' corresponds to my (3). The present taxonomy differs from hers in two respects: it adds (2) as an intermediate type of point-based explanation; and it adds (4) as a kind of hybrid between historical and hypothetical genealogy, which, on Gardiner's taxonomy, are presented as distinct enterprises. I agree with Gardiner that they can be entirely distinct enterprises. But my concern here is to make room 
(1) paradigm-based explanation: identify an actual paradigm case of practice $X$, hypothesise its point, identify the needs it answers to, and use this instrumental relation to certain needs to elucidate practice X; (1) is exemplified by Fricker's account of blame (2016).

(2) prototype-based explanation: construct a model of target practice $X$, hypothesise the point of this proto-practice, identify the needs it answers to within the model, and use the model to identify analogous and disanalogous instrumental relations in target practice X; (2) has the character of Wittgensteinian explanations in terms of fictional objects of comparison whose similarities and dissimilarities to our ways of going on are meant to elucidate them. ${ }^{7}$

(3) generic pragmatic genealogy: on the basis of an initial hypothesis about the original point of target practice $X$, construct a dynamic model showing why creatures like us would develop a prototypical version of the target practice by identifying root needs generating a problem to which the proto-practice forms a salient solution; then consider the proto-practice's elaboration in response to further generic needs anticipatable from within the

for the hybrid form that I take Williams's genealogy to instantiate: the historically informed pragmatic genealogy that starts out from generic needs, but then draws on history to de-idealise its model and incorporate ever more socio-historically local needs.

7 'Our clear and simple language-games are not preliminary studies for a future regimentation of language - as it were, first approximations, ignoring friction and air resistance. Rather, the language-games stand there as objects of comparison which, through similarities and dissimilarities, are meant to throw light on features of our language' (Wittgenstein 2009, §130). For a discussion of Wittgenstein's relation to genealogy, see Bangu (2018); Glock (2008a, 2008b, 2017) and particularly Glock (2006, pp. 296-303), where Glock compares and contrasts Wittgenstein's 'remarks on the natural history of human beings' (Wittgenstein 2009, §415) with Williams's genealogical method. 
model; the closer this brings us to some generic form of the target practice, the better the genealogist's claim to having identified its practical origins and what it does for us; (3) is exemplified by Craig's genealogy of the concept of knowledge (1990).

(4) pragmatic genealogy tailored to a socio-historical situation: on the basis of an initial hypothesis about the original point of target practice $X$, construct a dynamic model showing why creatures like us would go in for a prototypical version of the target practice by identifying root needs generating a problem to which the protopractice forms a salient solution; consider the proto-practice's elaboration in response to further generic needs anticipatable from within the model; then incorporate into the model increasingly socio-historically local needs which history tells us arose, and consider the proto-practice's elaboration in response to these more local needs; the closer this brings us to our local form of the target practice, the better the genealogist's claim to having identified that practice's practical origins and what it does for us now and around here; (4) is exemplified by Williams's genealogy of truthfulness (2002) and by his construction of a political concept of freedom tailored to our needs as liberals living under modernity (2005).

This typology already conveys something of the understanding of pragmatic genealogy I want to work with, but it will be helpful to flesh out what exactly pragmatic genealogy involves on the conception of it that I want to defend. On this conception, pragmatic genealogy stands to more regularly historiographical genealogy much as sense-making in terms of practical pressures stands to sense-making in terms of causalhistorical processes. Imagine having to explain to someone utterly unfamiliar with our culture why a car has the shape it does. One could do it by enumerating the stages of the car's actual formation on the 
assembly line, thereby describing the causal construction of the car; or one could explain the design of a finished car as reflecting a series of needs, thereby offering a pragmatic reconstruction of the car. ${ }^{8}$ Most basically, the design of a car reflects a need for mobility; but it is further determined by the need to see practically relevant parts of one's surroundings, the need to stay warm and dry, the need to sit comfortably-and so on, down to the need to follow socio-historically local aesthetic trends. Picture a computer animation starting out from a primitive geometrical shape and gradually reaching something recognisably car-like by successively factoring in the various needs of car-users and warping the shape to meet them. The stages of this formation process would not correspond to the steps involved in actually assembling a car. But they would reveal how various aspects of car design reflect and answer to a specific combination of needs.

Similarly, the primary target system of a pragmatic genealogical model is the set of needs that have gone into shaping our conceptual practices; generalising the interpretation of Craig's genealogy proposed by Martin Kusch and Robin McKenna (Kusch 2009, 2011, 2013; Kusch and McKenna 2018a), we can view pragmatic genealogies as dynamic models that work through idealisation and de-idealisation, aiming to offer perspicuous representations of the needs at the roots of our conceptual practices that are salient and illuminating for given purposes. ${ }^{9}$ The

8 The example is inspired by Kappel (2010).

9 The fact that they involve idealisation need not be a shortcoming of such models: the view that idealisation can enhance rather than impede understanding has been gaining increasing support since the 1980s; see Strevens (2008, ch. 8), Weisberg (2007), Elgin (2007), and the essays in Grimm, Baumberger, and Ammon (2016). We can distinguish three styles of idealisation. A pragmatic genealogy might resort either to idealisation by abstraction (i.e. the stripping away of non-essential features) - what is known as 'Aristotelian' idealisation (Cartwright 1989); or to idealisation by distortion (i.e. the operation with assumptions known to be false)—what is known as 'Galilean' idealisation (McMullin 1985); or to the mixture of both which is known as 'caricature' (Frigg and Hartmann 2017). See Kusch and McKenna (2018a) for further discussion. 
'fictionalising' of pragmatic genealogy is thus nothing new-fangled or mysterious; it is the fictionalising of model-building, and prima facie neither more nor less suspicious than models in the social and natural sciences, or than models in the rest of philosophy. ${ }^{10}$

Yet pragmatic genealogy not only enriches the consideration of the actual with that of the hypothetical; it also seeks to turn static into dynamic understanding: to help us understand not just how our conceptual practices reflect certain generic needs, but also how they reflect a complex history involving the recalibration, elaboration, or elimination of needs as well as the addition of new needs. This is why the models of pragmatic genealogy are dynamic models-models with a time axis, constrained by the demand that the models depict needs we have actually had, derive needs from needs in plausible and tractable ways, and issue in conceptual practices we recognise.

Two steps are involved in giving such pragmatic genealogies, the first involving idealisation, the second de-idealisation: (Step 1) render plausible a hypothesis about why creatures of our ilk would go in for a prototype of the conceptual practice we have-call this the 'protopractice', an idealised version of a conceptual practice that need not be realised in our actual practices; ${ }^{11}$ (Step 2) explain how we got from the proto-practice to the practice we actually have-call this the 'target practice'. The pragmatic genealogy must identify in what respects, if any, the proto-practice still differs from the target practice, for it is reaching something like the practice we know which provides what in the theory

${ }^{10}$ For a defence of model-building in philosophy, see Williamson (2017).

${ }^{11}$ Idealisation is what gets us from our actual practices to a prototypical version of a particular conceptual practice which need not be realised in our actual practices. A paradigm case of a conceptual practice, by contrast, is necessarily realised in our actual practices. But for our purposes, little depends on this last claim-if one treats 'paradigm case' as another name for prototypes reached through idealisation, Fricker would be engaged in (2), prototype-based explanation, and would be dispensing with the historicising but not with the fictionalising. 
of models is known as 'external validation' (Kusch 2013, p. 93). To this end, the model must be de-idealised in the direction of our cultural situation by (a) describing the proto-practice's primary elaboration, i.e. its development driven by the practical pressures internal to the model, such as the foreseeable problems which the original solution offered by the proto-practice will bring in its wake (this is what Craig does when he considers how a concept of proto-knowledge indexed to the subject's needs and capacities would be driven to become increasingly independent from those needs and capacities); ${ }^{12}$ and (b) describing the proto-practice's secondary elaboration, i.e. its development driven by the introduction of increasingly socio-historically local needs into the model and the new problems that come with them (this is what Williams does when he considers the extension of truthfulness to the distant past in Thucydides's time and its elaboration into the value of authenticity in the Romantic period). ${ }^{13}$ Both the primary and the secondary elaboration can be additive rather than transformative, which helps account for the internal diversity in the resulting practice. New forms of the proto-practice may come to rest alongside their predecessor instead of replacing it. $^{14}$

Insofar as the dynamic models of a pragmatic genealogy successively incorporate ever more socio-historically local needs, they can be said to move beyond the categorical divide between hypothetical and historical genealogy: they constitute a hybrid form that is clearly an idealised model rather than a description of actual history, but that also genuinely

12 See Craig (1990, pp. 82-97; 1993, pp. 81-115). See also Queloz (2019), Kusch (2009, 2011, 2013), and Kusch and McKenna (2018a, 2018b) for accounts of this process of objectivisation.

${ }^{13}$ See Williams (2002, chs. 7 and 8, respectively) as well as the reconstruction of Williams's genealogy in Queloz (2018b).

14 See Kusch $(2009,2013)$ for an account of Craig's genealogy that emphasises the importance of additive development. 
historicises the target practice by exhibiting it as the product of a complex historical accumulation of needs. Although history can inform the dynamic models of pragmatic genealogies, it is not the primary purpose of these models to mirror historical development; it is rather to extricate from history the main practical pressures and dynamics that have shaped our conceptual practices and that help us understand their retention, elaboration, and differentiation into a variety of forms.

An instructive example of a historically informed pragmatic genealogy is Williams's genealogy of truthfulness, i.e. of the virtues of accuracy and sincerity (2002). Williams starts out from a state-of-nature model depicting a basic epistemic predicament: human beings need information; but already the sheer fact that they are in different places at different times means that there are strong practical pressures on them not just to rely on their five senses in acquiring it, but to cooperate, in particular by engaging in an epistemic division of labour whereby information is pooled; this in turn means that they need to cultivate the dispositions that make good contributors to the pool: centrally, the prototypical forms of accuracy and sincerity that Williams (capitalising the terms to mark their technical nature) labels 'Accuracy' and 'Sincerity'. But since the practical value of these dispositions consists in large part not in their instrumental value for the individual who manifests them, but in their advantageousness to others, Accuracy and Sincerity need to come to be regarded as dispositions worth having for their own sake-as virtues - if the practice of effective information pooling is not to succumb to free riders. For this to be the case, people need to be able to make sense of these dispositions as virtues, which requires being able to relate them to other things that they value and to their emotions.

But to understand how all these generic needs have actually been satisfied 'now and around here', and how our form of truthfulness moreover has been 'changed, transformed, differently embodied, ex- 
tended and so on' (Williams 2007, p. 132) in answer to many further and more historically local needs, we need to de-idealise our generic model in our direction by incorporating increasingly local needs. We can then explain further elaborations of Accuracy and Sincerity until we reach something resembling the conceptual practices we know (Williams 2006, pp. 191-92; 2014). This is why Williams de-idealises his dynamic model of truthfulness by factoring in first the local needs of the ancient Greeks that led to truthfulness' extension to the distant past, then the even more local needs of eighteenth-century society that led to truthfulness' elaboration into a demand for authenticity, and finally the extremely local need of modern-day liberals to cultivate truthfulness about political history in order to maintain a sense of what can go wrong if individuals cede too many of their rights to the state (Williams 2002, pp. 265-66). In tailoring his dynamic model to the cultural situation that is more specifically ours, Williams seeks to offer a perspicuous representation of the entangled collection of historically accumulated needs to which truthfulness answers and hence of the variety of respects in which truthfulness is worth having. This representation enables us to place and relate these aspects of truthfulness, thereby giving us a sense of which aspects are explanatorily prior to which, how pressing or ineluctable the needs are to which they respond, and what historical circumstances these needs depend on. In a phrase we shall return to, this type of genealogy helps us situate aspects of truthfulness and the needs they answer to 'in a philosophical and historical space' (Williams 2005, p. 76). Williams's elaboration of Craig's methodology thus corresponds to the move from generic pragmatic genealogy to pragmatic genealogy tailored to a socio-historical situation.

Given this understanding of pragmatic genealogy, the question now is when and why we should move from paradigm-based explanation to pragmatic genealogy. Sometimes, paradigm-based explanation may be 
just what we need. ${ }^{15}$ But as we shall now see, there are cases where we still have reason to engage in pragmatic genealogy.

\section{Nietzsche's Challenge}

In order to understand the relevance of pragmatic genealogy to pointbased theorising, a methodological remark of Nietzsche's-the archgenealogist-provides a useful entry-point. It is well-known that $\mathrm{Ni}$ etzsche takes a dim view of philosophers' historical sense. But in the Genealogy, he rebukes the 'English genealogists' specifically for thinking ahistorically in assuming that there is an instrumental connection between our practices and timeless human needs (GM, Preface, §4, I, §2, II, §§12-13). ${ }^{16}$ Both we and our practices change, and philosophers will be led astray if they ignore the history that lies between the 'Darwinian beast' and the 'modern milquetoast' (GM, Preface, §7). This amounts to a challenge-call it Nietzsche's challenge-for all point-based explanations from paradigm-based explanation to pragmatic genealogy. We might offer point-based explanations in an experimental spirit, to see how far

${ }^{15}$ Suppose we were puzzled about the nature of a certain item we talk about, as J. M. Keynes was puzzled about the nature of probability. This led Keynes to suggest that probability was concerned with objective and unanalysable relations between propositions - to which F. P. Ramsey disarmingly objected that he himself did not perceive such relations, and suspected others did not perceive them either (1990, p. 57). Instead, Ramsey suggested that in the paradigm case, the point of probability statements was to express one's confidence or degree of belief in the occurrence of events in order to align one's degrees of belief with those of others and with the frequencies of events in a way that was conducive to successful action. Probability 'is a measurement of belief qua basis of action' (1990, p. 67). Ramsey demystified probability by relating it to human needs and actions rather than to mysterious objective relations, and in this context, this was just what was called for (Misak 2016, pp. 175-8).

${ }^{16}$ For evidence to the effect that the early Nietzsche himself practiced a fairly ahistorical form of pragmatic genealogy, see Queloz (2017, Manuscript). For a discussion of the role of history in Nietzsche's mature thought which argues that Nietzsche was a critic rather than an advocate of genealogical debunking, see Queloz and Cueni (2019). 
we get on the assumption that the connection obtains. But Nietzsche's challenge is that the connection may well not obtain, because we or our conceptual practices have changed, and then point-based explanations become-in more than one sense-pointless.

We learn much about the contours of point-based explanations by determining how they deal with Nietzsche's challenge. On the one hand, it raises the question of how they handle the historical inflection, differentiation, and repurposing of conceptual practices. On the other hand, it brings out that Fricker, Williams, and Craig-the modern-day 'English genealogists' - ground their explanations in highly generic needs - the 'humanly basic' and 'humanly necessary' (Fricker 2016, 180), 'universal requirements' (Williams 2014, p. 409), 'needs of the very basic kind' deriving from 'facts ... so general, indeed, that one cannot imagine their changing whilst anything we can still recognise as social life persists' (Craig 1990, pp. 4, 10). This raises the further question of whether point-based explanations are committed to thinking ahistorically about the needs to which they seek to relate our practices.

By putting a spotlight on the possibility of historical change, Nietzsche's challenge throws two features of point-based explanations into relief. As long as point-based explanations are understood as operating only with generic needs-needs which, according to our best understanding of them, humans have anyway - the following two conditions must be fulfilled for them to get a grip:

(i) the conceptual practice at issue must bear some instrumental relation to certain generic human needs-call this the Generic Needs Condition;

(ii) a paradigm case of the conceptual practice must be available which exhibits this relation-call this the Paradigm Case Condition. 
Nietzsche's challenge puts pressure on both conditions, since a great deal of change at the level either of our conceptual practices or of our needs may well result in a given conceptual practice fulfilling neither the Generic Needs Condition nor the Paradigm Case Condition.

My aim in this section is to examine how point-based explanations deal with Nietzsche's challenge, and how pragmatic genealogy in particular helps us do so. I shall first discuss the case in which the Generic Needs Condition is fulfilled while the Paradigm Case Condition is not; then the case in which it is uncertain even whether the Generic Needs Condition is fulfilled; and, lastly, the case in which neither condition is fulfilled.

\subsection{Constructing Paradigm Cases}

Consider the case in which the Generic Needs Condition is fulfilled while the Paradigm Case Condition is not: a conceptual practice still bears some instrumental relation to generic human needs, but it lacks a paradigm case exhibiting that relation. The problem for point-based explanations is then not that the connection between the conceptual practice and generic needs is severed by historical change. The Generic Needs Condition still holds. But the function once discharged by a single practice may now be jointly discharged by a constellation of different practices into which the original practice has differentiated in the course of history. Or the problem may be that the Generic Needs Condition holds all too well-a multiplicity of functions served by a practice over time may have been layered into it to such a degree that a paradigm case becomes difficult to identify. Where repurposing only 'obscure[s]' (GM, II, §12) previous functions, practices can accumulate a rich historical deposit. There may then not be such a thing as the current point of a particular conceptual practice, because repeated alteration and repurposing have 
layered such a multitude of functions into it that neither a paradigm case nor an overall point can be recovered from the resulting mess. A good example-Nietzsche's own-is the practice of punishment:

[T] he history of its exploitation for the most diverse purposes, finally crystallizes into a kind of unity that is difficult to dissolve, difficult to analyze and - one must emphasize - is completely and utterly undefinable. (Today it is impossible to say for sure why we actually punish: all concepts in which an entire process is semiotically summarized elude definition; only that which has no history is definable). (GM, II, $\S 13)$

If we look back to the various functions a practice has discharged, we can discern 'how the elements of the synthesis change their valence and rearrange themselves accordingly, so that now this, now that element comes to the fore and dominates at the expense of the remaining ones', and how 'in some cases one element (say the purpose of deterrence) seems to cancel out all the rest of the elements' (GM, II, §13). But because a practice's function at any one time only seems to cancel out previous functions, a complex and internally diverse deposit can form which not only defies analysis in terms of necessary and sufficient conditions, but also elucidation by means of a paradigm case exhibiting its core function. Nietzsche goes on to list eleven other functions layered up in the practice. 'Punishment', he concludes, 'is overladen with functions of all kinds' (GM, II, §14). In dealing with practices of this sort, paradigmbased explanation will either fail to get a grip on the practice or distort our understanding of it by projecting a functional uniformity onto it which it does not possess.

One reaction to this would be for paradigm-based explanation to try to capture the multiplicity of functions in a conceptual practice through multiple paradigm-based explanations of it. ${ }^{17}$ But this will quickly seem

17 The concept of knowledge is another example of a conceptual practice that has invited multiple hypotheses concerning its function(s). Apart from Craig's contention that 
arbitrary and ad hoc. More importantly, it will raise the question of how the various functions relate to each other. Does pragmatic genealogy fare any better?

On one interpretation of pragmatic genealogy, which has been defended by Fricker and helps explain her shift from pragmatic genealogy to paradigm-based explanation, it does not fare better. ${ }^{18}$ What makes pragmatic genealogy and paradigm-based explanation equally powerful in Fricker's eyes is that she interprets the genealogies as not only starting out from a prototype, but as suggesting also that the prototype is really the paradigm case or core of our actual practice: 'The key is to see that ... what is claimed about the State of Nature-for instance, that it contains a concept or practice with such and such features-is really a claim about what is basic (or 'core') in our actual concept or practice' (Forthcoming, p. 7). On this interpretation, the two methods stand on an equal footing, because the temporal priority articulated by pragmatic genealogies is a metaphor for explanatory priority within our actual practice. The time axis of pragmatic genealogies really serves as an expository device: it allows us to organise internally diverse

it serves to flag good informants and the numerous elaborations of that hypothesis (Hannon 2013, 2015; Henderson 2011; Kusch and McKenna 2018b; McKenna 2014, 2015), its function has been thought to be to signal that inquiry is at an end (Kappel 2010; Kelp 2011; Rysiew 2012), to identify propositions we can treat as reasons for acting (McGrath 2015), to provide assurance (Lawlor 2013), to distinguish between blameless and blameworthy behaviour (Beebe 2012), or to honour the subject of knowledge attributions (Kusch 2009). See also Moore (1993), Kusch and McKenna (2018a), and Gerken (2017, chs. 3 and 9) as well as the essays in Greco and Henderson (2015) for overviews and critical discussions. I agree with Kusch and McKenna (2018a) that a conceptual practice can come to serve a plurality of functions in the course of its history, going from a single-purpose to a multipurpose tool, like a Swiss Army knife. To integrate those among the functional hypotheses that are compatible with each other, what is needed is a master model that brings order into the plurality of functions and indicates which are basic and which are after-thoughts. I argue below that pragmatic genealogy provides just such a master model that helps us place and relate the various functions in a philosophical and historical space.

18 See Fricker (Forthcoming); also Fricker (1998, 2010, 2016). 
practices by first isolating what are offered up as explanatorily basic features and then successively adding further, increasingly complex but recognisably derivative features into the picture. On this interpretation, pragmatic genealogies are really circuitous versions of paradigm-based explanations. ${ }^{19}$ This interpretation licenses the conclusion that the temporal dimension of pragmatic genealogies can safely be collapsed into the here and now as long as we find some other way of highlighting the explanatorily basic. And this is precisely the task shouldered by Fricker's paradigm cases.

Fricker's interpretation combines two ideas to form what we may call the actualist interpretation of pragmatic genealogy: (a) that the movement in a genealogy from earlier to later stages does not represent a temporal movement from our conjectured hominid past to the present, and is therefore far removed from the influential conception of genealogy as 'history, correctly practised'; ${ }^{\prime 20}$ and (b) that the primitive form of a practice considered in the state of nature actually stands for a paradigm case of our actual practice, and that therefore the genealogical derivation of the less basic from the more basic can be safely collapsed into a description of our actual ways of going on. This interpretation of pragmatic genealogy undeniably has much going for it. By reading genealogy as involving neither an inference from fiction to reality nor one from past to present, it alleviates worries about how fictional stateof-nature stories can tell us anything about reality, and it deflects the charge of the genetic fallacy, i.e. the alleged mistake of deducing claims about the present features of something from claims about its genesis.

19 Whether, on Fricker's interpretation, the difference between pragmatic genealogy and paradigm-based explanation reduces to a difference in presentation is a question we can leave open here. If this were the case, Fricker would have moved from a less to a more perspicuous way of doing the same thing.

20 Nehamas (1985,p. 246n1). This historiographical conception of genealogy is endorsed by Geuss (1999, pp. 22-23), Owen (2007, p. 143), Merrick (2009), and Migotti (2016). 
The main drawback of this actualist interpretation, however, is that it makes pragmatic genealogy just as vulnerable to Nietzsche's challenge as paradigm-based explanation: both, on this reading, move from one element in our actual practices, which they present as explanatorily and practically basic, to other elements in those practices, which they present as derivative. This means that they both depend on there being, within our actual practices, a paradigmatic core form which is conspicuously functional given generic human needs and which can give us an explanatory and critical grip on the conceptual practice at issue. On the actualist interpretation, paradigm-based explanation and pragmatic genealogy are in the same boat.

But if, as I have suggested, we interpret pragmatic genealogy as hypothetical and dynamic rather than as actualist and static, it does fare better than paradigm-based explanation when paradigm cases are missing. We can join Fricker in maintaining (a), that the movement in a genealogy from earlier to later stages does not represent a temporal movement from our conjectured hominid past to the present, while denying (b), that it is a movement from paradigmatic to non-paradigmatic forms of our actual ways of going on. We can understand genealogy instead as a movement from a strongly idealised model of a practice to a less idealised model of it-as a movement of de-idealisation in the direction of our actual cultural situation.

An advantage of this dynamic model interpretation of pragmatic genealogy is that it does not depend on a paradigmatic form being extant; where history has failed to provide us with a paradigmatic form highlighting a practice's functional relation to generic needs, pragmatic genealogy can construct one. We can organise and elucidate the complex amalgam that is our target practice using a simplified practice. And we can then also model how we might have gotten here from there, where 'there' does not refer to some datable moment of emergence, 
but to an abstractly characterised basic predicament of which our present situation is a particular, socio-historically local manifestation. The resulting dynamic model will be able to serve as what Williams calls a 'plan' that helps us place and relate the various further developments and acquired functions of the practice 'in a philosophical and historical space' $(2005$, p. 76) — not the two-dimensional space of our current practice, as the actualist interpretation has it, but the three-dimensional space along the quasi-historical time axis of the dynamic model. In other words, pragmatic genealogy can act as a kind of master model that helps us situate, contextualise, and account for each of the different functions a practice acquired in different contexts, thereby imposing a form of order on the irreducibly varied synthesis that Nietzsche describes. The measure of the quality of that model will be its ability to make sense of the internal diversity of the practice and of the multiplicity of functions laid up in it.

An important consequence of this interpretation of pragmatic genealogy is that making sense of a target practice using a proto-practice does not commit us to the further claim that the proto-practice is now extant as the core of the target practice. Admittedly, Craig (2007, p. 191) seems to think both that his concept of proto-knowledge sheds light on the concept of knowledge and that it forms the core of our actual concept, but this has been deemed an unnecessary weakness in his account (Kusch 2011). Williams also sometimes uses the imagery of a core and its historical variations (2005, p. 76; 2014, p. 407), but whether he would be prepared to point to any actual instance of truthfulness as the core of truthful behaviour is less than clear. The core imagery seems to refer to what is central to the explanation rather than to our practices. However that may be, the important point for our purposes is that on the dynamic model interpretation, we can in fact coherently maintain all the following claims: first, that given certain generic needs 
that humans have anyway, they will need to see a certain function discharged, and we can illuminatingly construct a prototype of what a conceptual practice discharging it might look like; second, that this function is being discharged by our current conceptual practices; and third, that there is no one core form of our conceptual practices which directly corresponds to the prototype and conspicuously discharges that function. Just because the prototype is explanatorily basic does not mean that it is, or has ever been, extant.

The idiom of core and historical variation (Williams 2014, p. 407) or periphery (Fricker 2010) can be misleading in that regard, as it encourages thinking of the evolution of our conceptual practices on the model of a snowball: the original core accumulates additional layers as it rolls down the slopes of history, but by the time it ends up in our valley, though there are various accretions, the core is still there. ${ }^{21}$ This is an improvement on the 'English genealogists' that Nietzsche rebukes for simply equating the current function of our practices with their original function. But we can take the injunction to think historically about functions a step further. Just as a snowball may encounter an obstacle that leads it to break up into pieces which roll down different paths and grow into different shapes, a conceptual practice may differentiate into a family of related practices in response to a differentiation in needs, each practice tailored to specific contexts. They may still jointly discharge the function which the practice originally emerged to discharge; but there may be no one form of the practice that is in any sense the 'core' form.

Whether or not such 'core' or paradigm cases are available is of course not clear a priori, and the value of paradigm-based explanation is best appreciated if we understand it as being offered in an experimental spirit: we hypothesise a candidate paradigm case in order to see whether

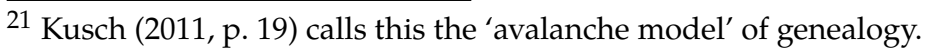


there is indeed a plausible paradigm case available. But if not, I have been arguing, all is not lost for point-based explanations. We can then fall back on pragmatic genealogy and try to derive explanatory enlightenment from the construction of a prototype, together with an account of why our actual ways of going on have come to differ from it.

\subsection{The Roots of Continuity}

So far, we have assumed that the Generic Needs Condition obtains: that the conceptual practice at issue still bears some instrumental relation to generic human needs. But why, once we are mindful of the wide array of contingencies and reinterpretations of which our practices are the product, should we remain confident that this is so? Nietzsche's challenge reminds us that we must be wary of the philosopher's foible of mistaking a failure of imagination for an insight into necessity.

Here also pragmatic genealogy proves a valuable addition to our repertoire. A pragmatic genealogy can be seen as an argumentative chain underscoring the assumption that a practice is a functional solution to some predicament we are bound to face on a continuous basis. It can reveal complicated instrumental relations between our practices and our needs even when we do not know they are there, and when the blank assertion that they obtain would not by itself be enough to convince.

The developmental narrative of a pragmatic genealogy is best understood as a derivation of needs from needs: humans have a need for $A$, hence a need for $B, \ldots$, hence a need for $X$, where $X$ is the prototypical form of the target practice. This gives pragmatic genealogy an edge over approaches that limit themselves to pointing out how a given practice is functional relative to one particular set of needs-how blame serves a need for moral alignment, say, or how talk of probabilities serves a 
need to communicate and adjust our confidence in the occurrence of events. In the genealogical mode, we can present these fairly sophisticated needs as growing out of more primitive needs, and these out of even more primitive ones, until we reach what we are willing to regard as needs we uncontroversially have anyway. This enables us to derive needs we are not disposed to think we continuously have (e.g., a practical need to value accuracy and sincerity intrinsically) from needs we are disposed to think we continuously have (e.g., a practical need for information and cooperation). When a function is being ascribed to something which we did not necessarily expect to be functional at all-to such venerable ideas as knowledge, justice, or truthfulness, for example-tracing out a chain of practical demands linking these highflown abstracta to mundane concerns can make us more comfortable with the idea that these are functional responses to enduring challenges. Few will balk at the suggestion that our practice of thinking in terms of the concept water answers to enduring human needs; but the suggestion that concepts like knowledge, justice, or truthfulness do the same may sound at first rather like the Panglossian claim that the bridge of the nose is there to rest glasses on. Pragmatic genealogy can help alleviate these worries by deriving needs we did not know we had from needs we knew we had, thereby revealing even the seemingly ethereal or transient to be firmly rooted in enduring human concerns. In this sense, a state-of-nature model can act as a representation of the roots of continuity in the demands we face.

Moreover, the genealogical perspective allows us to argue that the proto-practice we seek to present as a solution to a problem could in fact have emerged without assuming implausible forms of foresight or intent. A practice may constitute a solution to a problem, but that solution may be inaccessible through individual instrumental reasoning-for instance, because it requires solving a coordination problem, or because 
it involves the essentially social process of constructing an intrinsic value. $^{22}$ In such cases, one way in which genealogical explanation can add to our understanding is by sketching a mechanism through which such obstacles might be overcome quite naturally, without much foresight or intent. ${ }^{23}$

A pragmatic genealogy can thus do more to earn its conclusion than a non-genealogical ascription of functionality. If we accept, first, that the generic needs which operate as premises in the story are needs we share in some form; second, that the derivation from them of less primitive needs is valid; and third, that there are ways in which these might have driven us to develop certain conceptual practices in response, then we shall have been given a reason to expect there to be, in our actual cultural situation, some conceptual practice, or perhaps a constellation of conceptual practices, which is instrumental to the satisfaction of generic needs-and therefore a reason to think that the Generic Needs Condition obtains.

\subsection{Incorporating Local Needs}

Lastly, the deepest engagement with Nietzsche's challenge is demanded when both the Generic Needs Condition and the Paradigm Case Condition cease to obtain. This will be the case to the extent to which practices are local outgrowths of history that do not bear illuminating relations to generic human needs. Must point-based explanations, and in particular pragmatic genealogies, lose all explanatory force once the connection to generic needs gives out, or can they still provide illumination even then?

22 Williams (2000, p. 156n6).

23 A well-known example is Hume's genealogy of the virtue of 'justice' as respect for property (T,3.2.2). See Wiggins (2006), Garrett (2007) and Blackburn (2008) for interpretations germane to the present discussion. 
They can-by augmenting our understanding of conceptual practices, insofar as they fail to be amenable to elucidation by generic needs, with an understanding in terms of their point given local needs. It is tempting to think that local needs lie beyond the ken of point-based explanation, since, as we saw, Craig, Williams, and Fricker all make a point of grounding their explanations in highly generic and humanly basic needs. Does this imply a methodological restriction to universal or generic needs? Are point-based explanations called for only in dealing with anthropological necessities? Craig explicitly denies this:

Any society that has a well-developed language... consists of creatures that have reached a considerable degree of mental complexity. Any number of different sorts of need may, for all we know to the contrary, follow in the wake of this complexity; so there is no a priori reason to think that we are tied by methodological principles to considering only needs of the very basic kind that I have actually tried to restrict myself to. (1990, p. 4)

As this passage brings out, understanding our conceptual practices as tools responding to our needs should not commit us to understanding them only in terms of generic needs. Such a focus on the needs we have anyway to the exclusion of needs we acquired or lost in the course of history would again be vulnerable to the Nietzschean charge of ahistorical thinking. To view all our conceptual practices as tools helping us cope with needs we have anyway would be to fall into the kind of reductive naturalism which assumes, as Robert Brandom (2011, p. 140) puts it, that we could safely dismiss Romantic poetry by asking what it has ever done for our biological fitness.

Rightly understood, point-based explanations are not methodologically restricted to elucidating the point of our conceptual practices in the light of universal or generic needs. We might in principle even construct a state-of-nature model starting out from requirements that are fundamental and non-negotiable for us, in full knowledge of the fact 
that other cultures did not share these needs. A precedent is the Original Position as conceived by John Rawls in his later work (1993): contrary to his earlier interpretation in A Theory of Justice (1971), the later Rawls no longer viewed the model of the Original Position as a representation of a timeless problem that any society faces, but as a representation of a local problem: the problem of arriving at a conception of justice that is justifiable to $u s$, the citizens of heterogenous modern constitutional democracies. ${ }^{24}$

There is thus no reason why point-based explanations cannot get a grip on socio-historically local practices by relating them to local needs. This is a strategy that is also open to paradigm-based explanation. But there are two respects in which pragmatic genealogy proves particularly apt at dealing with local needs.

First, while paradigm-based explanation only relates current conceptual practices to current needs, pragmatic genealogy can exploit the fact that the connection between needs and practices also holds dynamically: it can additionally relate changes in conceptual practices to changes in needs. ${ }^{25}$ The grip that pragmatic genealogy gives us on changes in our conceptual practices is a further respect in which it adds something to paradigm-based explanation. This equips it to answer

${ }^{24}$ See also Queloz and Cueni (Manuscript).

${ }^{25}$ Changes in needs can in turn be related to social change. In this sense, as Kusch (2009, p. 70) highlights, genealogy systematically exploits the connection between the evolution of conceptual practices and the development of social relations. A good example-again augmenting generic pragmatic genealogy with local needs-is Kusch's elaboration of Craig's genealogy of knowledge on the basis of Steven Shapin's A Social History of Truth (1994). Kusch seeks to explain the observation that to attribute knowledge is to attribute status, freedom, and social power in terms of inquirers' need to identify reliable-because disinterested-informants plus the historical circumstance that in seventeenth-century England, social relations were such that a concept tracking disinterested informants would end up tracking nobility, financial independence, freedom, and social power (Kusch 2009, pp. 83-87). See also Gardiner (2015, pp. 38-39) for an illuminating discussion of this example. 
Nietzsche's challenge by incorporating historical change into its dynamic model. It does this by incorporating local needs into the dynamic model, turning it into an historically informed dynamic model in which changes in historical circumstances are reflected as changes in our needs. This allows pragmatic genealogy to render conceptual change rationally intelligible: to understand why, as we saw in the reconstruction of Williams's genealogy of truthfulness, ideas of truthfulness changed at certain junctures in history, and thus ultimately why our ideas of truthfulness came to have the specific shape they have as opposed to other shapes they have had in the past. Of course, what needs concept-users find themselves with can in turn be explained in terms of alterations in their circumstances, and in this sense, what needs we find ourselves with will to some extent only be causally intelligible as the result of contingent historical change. But our conceptual practices are no less necessary for that. Insofar as the needs we contingently have generate real problems that necessitate solutions, the conceptual practices providing those solutions will be necessary for us. Given certain needs, however local, certain conceptual practices could not viably be different. They provide necessary solutions to contingent problems.

Second, pragmatic genealogy can offer what we might call a comprehensive view of a conceptual practice: one that brings out both the respects in which it serves generic needs and the respects in which it serves increasingly local needs while also placing and relating these aspects of the practice in its dynamic model, thereby situating them in a historical and philosophical space. It situates them in a historical space insofar as we understand which aspects of the practice are the product of highly general facts about us, and which are the product of more particular historical circumstances (as well as which circumstances these are and in what order they arise). And we situate them in a philosophical space insofar as we understand their relative importance 
and ineluctability: Do they answer to pressing needs? Are these needs we cannot but have, or are they needs we can eradicate by changing our circumstances?

Apart from Williams's genealogy of truthfulness, another example of a pragmatic genealogy that achieves such a comprehensive view of a conceptual practice by bringing out, placing, and relating the respects in which it answers to generic and local needs is Williams's account of liberty 'as a value for us in our world' (2005, p. 75). He constructs a dynamic model beginning with the universal need for 'primitive freedom' - a pre-political notion of freedom from constraint by other individuals (Williams reserves the term 'liberty' for the political notion of freedom). In pursuing their primitive freedom, individuals will impinge on each other's freedom spheres, and one individual's desire satisfaction will be another individual's coercion. A basic problem emerges: where does one freedom sphere end and the other begin? Disagreement over this generates violence and instability. This gives rise to the need for a public conflict-resolver, an allocator of freedom spheres. But if this allocator of freedom spheres is not to replace private by public coercion, there needs to be a distinction between legitimate and illegitimate uses of public power. Consequently, there is a need for legitimating concepts that permit this distinction. But wherever this need is manifest, the required legitimating concepts will have to be fleshed out in terms of a legitimation story, which, by drawing for example on transcendent sources of authority, must justify to each citizen why public power can be used to restrict people's freedom in some ways rather than others. The basic political problem highlighted by Williams's genealogy is that we need some legitimating concepts enabling a distinction between good and bad government. But these needs cannot by themselves determine which concepts these will 
be-whether the legitimation stories will draw on the idea of liberty, for example, or on theological or transcendent sources of legitimacy.

If we take more local needs and circumstances into account, however, it becomes clearer why liberty is so important to a more local 'us'. Under conditions of modernity, truthful inquiry and historical selfconsciousness have eroded many myths and narratives that formed the stuff of past legitimation stories, leaving us with less material for our legitimation stories; and once these sources of legitimation fall away, there will be a stronger presumption in favour of citizens' freedom to do what they want. We are more concerned with liberty than past societies because 'we start, in a sense, with less' (2005, p. 95)—in particular, less by which to justify restricting liberty. This not only helps explain our special concern with liberty, but also shows that we are rightly more concerned with liberty by presenting our heightened concern with liberty as an expression of truthfulness.

The value of a comprehensive view of our conceptual practices is that it safeguards us from two ways in which our view of them can be overly simplistic: one is by understanding the practice exclusively as a response to generic needs when it also answers to local needs; the other is by understanding the practice exclusively as a response to local needs when it also answers to generic needs. Both kinds of simplifications should be avoided, because we ideally want to understand all the respects in which a practice answers to needs-for explanatory purposes, of course, but quite particularly also for revisionary or critical purposes. If we fixate on generic needs that make a conceptual practice seem well worth having, we run the risk of missing the respects in which its local form also serves local needs that may be problematic, and to that extent give us reason to abandon or alter the conceptual practice. Conversely, when we find that a conceptual practice serves local needs we find problematic, and to that extent have reason to abandon or alter the practice, this insight should 
be enriched with a grasp of the extent to which the practice also serves generic needs of a very basic and hence easily overlooked sort, because this will show us how we should not go about tampering with our conceptual practices by alerting us to what we stand to lose. If Hume's pragmatic genealogy of property $(T, 3.2 .2)$ is sound, for example, then some form of property is something we cannot do without if society is not to descend into chaos and violent conflict over external goods, however correct Rousseau's (1977) diagnosis that certain elaborations of the institution of property also serve the problematic needs of insatiable individuals suffering from inflamed amour-propre. ${ }^{26}$

Pragmatic genealogy, then, does much to help us meet Nietzsche's challenge. First, while paradigm-based explanation depends on practices including a suitably paradigmatic core form that is subservient to human needs and will fail to get a grip where such a form is unavailable, pragmatic genealogy — on the dynamic model interpretation-can construct a proto-practice by which to shed light on the target practice. Second, pragmatic genealogy need not blithely assume that generic human needs are still informative, but can offer an argument for it, an argument which might reveal instrumental relations between our conceptual practices and our needs which we did not know were there. And third, insofar as Nietzsche's challenge is indeed devastating to the attempt of any point-based explanation to elucidate our current ways of going on in the light of generic human needs, such explanations can still provide insight by highlighting the point of a practice given local needs. History - and more broadly, social understanding-should inform our model-building not only in selecting the needs and the hypothesis about the original point we start out from, but also in incorporating

${ }^{26}$ On Hume's genealogy of property, see Baier $(1988,2010)$; Cohon (2008). On Rousseau's more critical genealogy of self-love and its harnessing of property, see Neuhouser $(2012,2014)$. 
increasingly local needs into our genealogy. This enables us to link generic prototypes to the conceptual practices we actually find now and around here, thereby bringing out and situating the respects in which these simultaneously answer to needs ranging from the highly generic to the extremely local.

\section{Conclusion}

In light of Nietzsche's challenge, paradigm-based explanation thus turns out not to be enough. Point-based explanations cannot entirely dispense with the fictionalising and historicising of genealogy. We need pragmatic genealogy, and we need to conceive of it not as a baroque form of paradigm-based explanation, but as a genuine elaboration of it that expands the repertoire of point-based explanation with dynamic models capable of situating generic and local needs in a historical and philosophical space. Pragmatic genealogy's fictionalising, modelbuilding aspect earns its keep by helping us achieve a grip where paradigm-based explanation fails to get a grip, namely on historically inflected conceptual practices that lack a paradigm case or an obvious connection to generic human needs. And its historicising, dynamic aspect earns its keep by helping us de-idealise our models in order to understand how our conceptual practices reflect a complex historical amalgamation of generic and local practical pressures. For these reasons, pragmatic genealogy proves an irreplaceable tool in the toolkit of those who seek to understand our practices in terms of their point.

If we want to move beyond potentially simplistic views of our conceptual practices that focus exclusively on how they serve highly generic needs, therefore, we would do well to resort to the historically informed dynamic models of pragmatic genealogy, because these are tailored to convey a nuanced and comprehensive view of our conceptual 
practices as reflecting a combination of generic and socio-historically local needs. This conclusion holds equally for approaches suffering from the reverse problem of focusing exclusively on how a conceptual practice serves highly local needs, and thus risk missing the respects in which the practice also serves important generic needs. Here also, both for explanatory and for revisionary purposes, we want a nuanced and comprehensive view. When we find that a practice serves local needs we find problematic, we should supplement this insight with an understanding of the extent to which the practice also serves generic needs of a familiar and easily overlooked sort. This need not mean that we should not tamper with the practice. But it will help us revise it responsibly.

The method of pragmatic genealogy, which shows how the present shape of a conceptual practice reflects a complex historical accumulation of old and generic as well as new and local needs, is uniquely suited to helping us understand such nuances. And these nuances are crucial if we are to make sense, not just of the practical significance our conceptual practices would have were we as rough-hewn as the prototypical humanoids depicted in the state of nature, or of the significance they would have if they answered solely to parochial needs, but of the significance they actually have, now and around here. ${ }^{27}$

${ }^{27}$ I would like to thank the Editors and Associate Editors of MIND as well as two anonymous reviewers for their exceptionally helpful comments. I am also very grateful to Rebekka Hufendiek, Damian Cueni, and Markus Wild for putting a great deal of thought into this paper at key stages. A third debt of gratitude is to Simon Blackburn, Anne Meylan, Martin Kusch, Robin McKenna, Muriel Leuenberger, Jelscha Schmid, Deborah Mühlebach, Jan Müller, Christian Budnik, Anna Goppel, Markus Stepanians, Andreas Müller, Andreas Cassee, and all those who participated in discussions of the paper at the Universities of Basel and Bern. This work was supported by Doc.CH grant P0BSP1_162025 of the Swiss National Science Foundation. 


\section{Bibliography}

Baier, Annette. 1988. 'Hume's Account of Social Artifice: Its Origins and Originality'. Ethics. 98(4): 757-78.

- 2010. The Cautious Jealous Virtue: Hume on Justice. Cambridge, MA: Harvard University Press.

Bangu, Sorin. 2018. 'Later Wittgenstein and the Genealogy of Mathematical Necessity'. In Wittgenstein and Naturalism. Edited by Kevin M. Cahill and Thomas Raleigh, 151-173. London and New York: Routledge.

Beebe, James R. 2012. 'Social Functions of Knowledge Attributions'. In Knowledge Ascriptions. Edited by Jessica Brown and Mikkel Gerken, 220-242. Oxford: Oxford University Press.

Blackburn, Simon. 2008. How to Read Hume. London: Granta.

—. 2013a. 'Pragmatism in Philosophy: The Hidden Alternative'. Philosophic Exchange. 41(1): 2-13.

-. 2013b. 'Pragmatism: All or Some?'. In Expressivism, Pragmatism and Representationalism. Edited by Huw Price, 67-84. Cambridge: Cambridge University Press.

Brandom, Robert. 2011. 'Vocabularies of Pragmatism: Synthesizing Naturalism and Historicism'. In Perspectives on Pragmatism: Classical, Recent, and Contemporary, 116-157. Cambridge, MA: Harvard University Press.

Cartwright, Nancy. 1989. Nature's Capacities and Their Measurement. Oxford: Oxford University Press.

Cohon, Rachel. 2008. Hume's Morality: Feeling and Fabrication. New York: Oxford University Press.

Craig, Edward. 1990. Knowledge and the State of Nature: An Essay in Conceptual Synthesis. Oxford: Clarendon Press. 
—. 1993. Was wir wissen können: Pragmatische Untersuchungen zum Wissensbegriff. Wittgenstein-Vorlesungen der Universität Bayreuth. Edited by Wilhelm Vossenkuhl. Frankfurt am Main: Suhrkamp.

—. 2007. 'Genealogies and the State of Nature'. In Bernard Williams. Edited by Alan Thomas, 181-200. Cambridge: Cambridge University Press.

Dutilh Novaes, Catarina. 2015. 'Conceptual Genealogy for Analytic Philosophy'. In Beyond the Analytic-Continental Divide. Edited by Jeffrey A. Bell, Andrew Culrofello and Paul M. Livingston, 75-110. Routledge.

Elgin, Catherine Z. 2007. 'Understanding and the Facts'. Philosophical Studies. 132(1): 33-42.

Fricker, Elizabeth. 2015. 'Know First, Tell Later: The Truth about Craig on Knowledge'. In Epistemic Evaluation: Purposeful Epistemology. Edited by John Greco and David Henderson, 46-86. Oxford: Oxford University Press.

Fricker, Miranda. 1998. 'Rational Authority and Social Power: Towards a Truly Social Epistemology'. Proceedings of the Aristotelian Society. 98(2): 159-177.

—. 2007. Epistemic Injustice: Power and the Ethics of Knowing. Oxford and New York: Oxford University Press.

- 2010. 'Scepticism and the Genealogy of Knowledge: Situating Epistemology in Time'. In Social Epistemology. Edited by A. Haddock, A. Millar and D. Pritchard, 51-68. Oxford: Oxford University Press.

—. 2016. 'What's the Point of Blame? A Paradigm Based Explanation'. Noûs. 50(1): 165-183.

—. Forthcoming. 'Forgiveness: An Ordered Pluralism'. Australasian Philosophical Review.

Frigg, Roman, and Stephan Hartmann. 2017. Models in Science. In The Stanford Encyclopedia of Philosophy edited by Edward N. Zalta. 
Gardiner, Georgi. 2015. 'Teleologies and the Methodology of Epistemology'. In Epistemic Evaluation: Purposeful Epistemology. Edited by John Greco and David Henderson, 31-45. Oxford: Oxford University Press.

Garrett, Don. 2007. 'The First Motive to Justice: Hume's Circle Argument Squared'. Hume Studies. 33(2): 257-288.

Gerken, Mikkel. 2017. On Folk Epistemology: How we Think and Talk about Knowledge. Oxford: Oxford University Press.

Geuss, Raymond. 1999. 'Nietzsche and Genealogy'. In Morality, Culture and History, 1-28. Cambridge: Cambridge University Press.

Glock, Hans-Johann. 2006. 'Wittgenstein and History'. In Wittgenstein: The Philosopher and His Works. Edited by A. Pichler and S. Säätelä, 277-303. Frankfurt a. M.: Ontos.

—. 2008a. 'Analytic Philosophy and History: A Mismatch?'. Mind. 117(468): 867-897.

- 2008b. What is Analytic Philosophy? Cambridge: Cambridge University Press.

- 2017. 'Philosophy and Philosophical Method'. In A Companion to Wittgenstein. Edited by Hans-Johann Glock and John Hyman, 231-251. Chichester: Wiley-Blackwell.

Greco, John, and David Henderson, eds. 2015. Epistemic Evaluation: Purposeful Epistemology. Oxford: Oxford University Press.

Grimm, Stephen R., Christoph Baumberger, and Sabine Ammon, eds. 2016. Explaining Understanding: New Perspectives From Epistemology and Philosophy of Science. London: Routledge.

Hacking, Ian. 2005. 'Truthfulness'. Common Knowledge. 11(1): 160-172. Hannon, Michael. 2013. 'The Practical Origins of Epistemic Contextualism'. Erkenntnis. 78(4): 899-919. 10.1007/s10670-012-9426-z.

—. 2015. 'The Universal Core of Knowledge'. Synthese. 192(3): 769-786. 10.1007/s11229-014-0587-y. 
Henderson, David. 2011. 'Gate-Keeping Contextualism'. Episteme. 8(1): 83-98.

T: Hume, David. 2000. A Treatise of Human Nature. Edited by David Fate Norton and Mary J. Norton. Oxford: Oxford University Press.

Kappel, Klemens. 2010. 'On Saying That Someone Knows: Themes From Craig'. In Social Epistemology. Edited by Adrian Haddock, Alan Millar and Duncan Pritchard, 69-88. Oxford: Oxford University Press.

Kelp, Christoph. 2011. 'What's the Point of "Knowledge" Anyway?'. Episteme. 8(1): 53-66.

Koopman, Colin. 2009. 'Two Uses of Genealogy: Michel Foucault and Bernard Williams'. In Foucault's Legacy. Edited by C. G. Prado, 90-108. New York: Continuum.

-. 2013. Genealogy as Critique: Foucault and the Problems of Modernity. Bloomington and Indianapolis: Indiana University Press.

Kornblith, Hilary. 2011. 'Why Should We Care About the Concept of Knowledge?'. Episteme. 8(1): 38-52.

Kusch, Martin. 2009. 'Testimony and the Value of Knowledge'. In Epistemic Value. Edited by Adrian Haddock, Alan Millar and Duncan Pritchard, 60-94. Oxford: Oxford University Press.

- 2011. 'Knowledge and Certainties in the Epistemic State of Nature'. Episteme. 8(1): 6-23.

-. 2013. 'Naturalized Epistemology and the Genealogy of Knowledge'. In Contemporary Perspectives on Early Modern Philosophy: Nature and Norms in Thought. Edited by Martin Lenz and Anik Waldow, 87-100. Dordrecht and New York: Springer.

Kusch, Martin, and Robin McKenna. 2018a. 'The Genealogical Method in Epistemology'. Synthese. 10.1007/s11229-018-1675-1.

- 2018b. 'The Genealogy of Relativism and Absolutism'. In Metaepistemology: Realism and Anti-Realism. Edited by Christos Kyriacou and Robin McKenna, 217-239. New York: Palgrave Macmillan. 
Lawlor, Krista. 2013. Assurance: An Austinian View of Knowledge and Knowledge Claims. Oxford: Oxford University Press.

McGrath, Matthew. 2015. 'Two Purposes of Knowledge-Attribution and the Contextualism Debate'. In Epistemic Evaluation: Purposeful Epistemology. Edited by John Greco and David Henderson, 138-157. Oxford: Oxford University Press.

McKenna, Robin. 2014. 'Shifting Targets and Disagreements'. Australasian Journal of Philosophy. 92(4): 725-742.

-. 2015. 'Epistemic Contextualism Defended'. Synthese. 192(2): 363-383. McMullin, Ernan. 1985. 'Galilean idealization'. Studies in History and Philosophy of Science Part A. 16(3): 247-273.

Merrick, Allison M. 2009. 'On Nietzsche's Genealogical Mode of Inquiry'. Doctor of Philosophy, School of Humanities, University of Southampton.

Migotti, Mark. 2016. 'History, Genealogy, Nietzsche: Comments on Jesse Prinz, Genealogies of Morals: Nietzsche's Method Compared'. Journal of Nietzsche Studies. 47(2): 212-227. 10.5325/jnietstud.47.2.0212.

Misak, Cheryl. 2015. 'Pragmatism and the Function of Truth'. In Meaning Without Representation: Essays on Truth, Expression, Normativity, and Naturalism. Edited by Steven Gross, Nicholas Tebben and Michael Williams, 262-278. Oxford: Oxford University Press.

-. 2016. Cambridge Pragmatism: From Peirce and James to Ramsey and Wittgenstein. Oxford: Oxford University Press.

Moore, Adrian W. 1993. 'Ineffability and Reflection: An Outline of the Concept of Knowledge'. European Journal of Philosophy. 1(3): 285-308. 10.1111/j.1468-0378.1993.tb00087.x.

Nehamas, Alexander. 1985. Nietzsche: Life as Literature. Cambridge, MA: Harvard University Press.

Neuhouser, Frederick. 2012. 'The Critical Function of Genealogy in the Thought of J.-J. Rousseau'. Review of Politics. 74: 371-87. 
- 2014. Rousseau's Critique of Inequality: Reconstructing the Second Discourse. Cambridge: Cambridge University Press.

GM: Nietzsche, Friedrich. 1998. On the Genealogy of Morality. Translated by Maudemarie Clark and Alan J. Swensen. Indianapolis and Cambridge: Hackett.

Owen, David. 2007. Nietzsche's Genealogy of Morality. Stocksfield: Acumen.

Pettit, Philip. 2018. The Birth of Ethics: Reconstructing the Role and Nature of Morality. Edited by Kinch Hoekstra. Oxford and New York: Oxford University Press.

Price, Huw. 2011. Naturalism Without Mirrors. Oxford: Oxford University Press.

Price, Huw, Simon Blackburn, Robert Brandom, Paul Horwich, and Michael Williams. 2013. Expressivism, Pragmatism and Representationalism. Cambridge: Cambridge University Press.

Queloz, Matthieu. 2017. 'Nietzsche's Pragmatic Genealogy of Justice'. British Journal for the History of Philosophy. 25(4): 727-749. 10.1080/09608788.2016.1266462.

- 2018a. 'How Genealogies Can Affect the Space of Reasons'. Synthese. $10.1007 /$ s11229-018-1777-9.

—. 2018b. 'Williams's Pragmatic Genealogy and Self-Effacing Functionality'. Philosophers' Imprint. 18(17): 1-20. 2027/spo.3521354.0018.017.

- 2019. 'Genealogy and Knowledge-First Epistemology: A Mismatch?'. The Philosophical Quarterly. 69(274): 100-120. 10.1093/pq/pqy041.

-. Forthcoming. 'The Points of Concepts: Their Types, Tensions, and Connections'. Canadian Journal of Philosophy.

-. Manuscript. 'Nietzsche's English Genealogy of Truthfulness'.

Queloz, Matthieu, and Damian Cueni. 2019. 'Nietzsche as a Critic of Genealogical Debunking: Making Room for Naturalism Without Sub- 
version'. The Monist: An International Journal of General Philosophical Inquiry. 102(3).

\section{-. Manuscript. 'Left Wittgensteinianism'.}

Ramsey, Frank Plumpton. 1990. 'Truth and Probability'. In F. P. Ramsey: Philosophical Papers. Edited by D. H. Mellor, 52-94. Cambridge: Cambridge University Press.

Rawls, John. 1971. A Theory of Justice. Cambridge, MA, and London, England: Harvard University Press.

—. 1993. Political Liberalism. New York: Columbia University Press. Rousseau, Jean-Jacques. 1977. 'Discourse on the Origin and Foundations of Inequality among Men'. In The Discourses and Other Early Political Writings. Translated by Victor Gourevitch, 111-22. Cambridge: Cambridge University Press.

Rysiew, Patrick. 2012. 'Epistemic Scorekeeping'. In Knowledge Ascriptions. Edited by Jessica Brown and Mikkel Gerken, 270-294. Oxford: Oxford University Press.

Shapin, Steven. 1994. A Social History of Truth: Civility and Science in Seventeenth-Century England. Chicago: University of Chicago Press. Srinivasan, Amia. 2015. 'The Archimedean Urge'. Philosophical Perspectives. 29(1): 325-362.

Strevens, Michael. 2008. Depth: An Account of Scientific Explanation. Cambridge, MA: Harvard University Press.

Weisberg, Michael. 2007. 'Three Kinds of Idealization'. The Journal of Philosophy. 104: 639-659.

Wiggins, David. 2006. Ethics: Twelve Lectures on the Philosophy of Morality. Cambridge, MA: Harvard University Press.

Williams, Bernard. 2000. 'Naturalism and Genealogy'. In Morality, Reflection, and Ideology. Edited by Edward Harcourt, 148-161. Oxford: Oxford University Press. 
-. 2002. Truth and Truthfulness: An Essay in Genealogy. Princeton: Princeton University Press.

-. 2005. 'From Freedom to Liberty: The Construction of a Political Value'. In In the Beginning Was the Deed: Realism and Moralism in Political Argument. Edited by Geoffrey Hawthorne, 75-96. Princeton and Oxford: Princeton University Press.

-. 2006. 'Philosophy as a Humanistic Discipline'. In Philosophy as a Humanistic Discipline. Edited by Adrian W. Moore, 180-199. Princeton and Oxford: Princeton University Press.

- 2007. 'Truth and Truthfulness'. In What More Philosophers Think. Edited by Julian Baggini and Jeremy Stangroom, 130-146. London: Continuum.

-. 2014. 'Why Philosophy Needs History'. In Essays and Reviews 1959-2002. Edited by Michael Woods, 405-412. Princeton: Princeton University Press.

Williams, Michael. 2013. 'How Pragmatists can be Local Expressivists'. In Expressivism, Pragmatism and Representationalism. Edited by Huw Price, 128-144. Cambridge: Cambridge University Press.

Williamson, Timothy. 2017. 'Model-Building in Philosophy'. In Philosophy's Future: The Problem of Philosophical Progress. Edited by Russell Blackford and Damien Broderick, 159-172. Hoboken, NJ: Wiley-Blackwell.

Wittgenstein, Ludwig. 2009. Philosophical Investigations. Edited by P. M. S. Hacker and J. Schulte. Chichester, U.K.: Wiley-Blackwell. 